\title{
Integrated Subsurface Water Solutions for Coastal Wetland Restoration through Integrated Pump\&Treat and Aquifer Storage and Recovery (ASR) ${ }^{+}$
}

\author{
Martha Perdikaki 1,*, Andreas Kallioras 1, Klio Monokrousou 1, Christoforos Christoforidis 2, \\ Dimitris Iossifidis 2, Eri Bizani 2, Anastasios Zafeiropoulos ${ }^{3}$, Klisthenis Dimitriadis ${ }^{4}$, \\ Klaasjan Raat ${ }^{5}$, Gerard van den Berg ${ }^{5}$ and Christos Makropoulos ${ }^{1}$ \\ 1 School of Mining and Metallurgical Engineering, National Technical University of Athens, Athens 15780, \\ Greece; kallioras@metal.ntua.gr (A.K.); kmonokrousou@gmail.com (K.M.); cmakro@chi.civil.ntua.gr (C.M.) \\ 2 GtG Technologies S.A., Athens 14564, Greece; c.christophoridis@greenerthangreen.co (C.C.); \\ d.iossifidis@greenerthangreen.co (D.I.); e.bizani@greenerthangreen.co (E.B.) \\ 3 UBITECH Ltd., Athens 15231, Greece; azafeiropoulos@ubitech.eu \\ 4 Geoservice Ltd., Athens 11147, Greece; info@geoservice.gr \\ 5 KWR Water B.V., Nieuwegein 3430 BB, The Netherlands; klaasjan.Raat@kwrwater.nl (K.R.); \\ gerard.van.den.berg@kwrwater.nl (G.v.d.B.) \\ * Correspondence: mperdikaki@metal.ntua.gr; Tel.: +30-210-772-2113 \\ + Presented at the 3rd EWaS International Conference on "Insights on the Water-Energy-Food Nexus", \\ Lefkada Island, Greece, 27-30 June 2018. \\ Published: 3 August 2018
}

\begin{abstract}
Un-managed surface and groundwater exploitation in coastal areas usually leads to deterioration of such sensitive ecosystems by means of water resources degradation and/or increased salinity. The coastal partof Marathon is a typical Mediterranean hydro-environment that hosts a naturally occurring coastal wetland linked to a typical coastal and today degraded hydrogeological system of a semi-arid region. A smart engineered Subsurface-Water-Solution (SWS)system composed ofan optimised Pump \& Treat componentintegrated with an Aquifer Storage and Recovery (ASR) scheme in this area is envisagedcontribute to the remediationof the groundwater system and the wetland.
\end{abstract}

Keywords: Subsurface-Water-Solution; Managed Aquifer Recharge; Aquifer-Storage-Recovery; Pump \& Treat

\section{Introduction}

Coastal hydro-systems in arid and semi-arid areas around the world have been proved as valuable sources of water for multiple uses. In Circum-Mediterranean regions, wetlands are used as a vital source of water for everyday life activities connected to agriculture, tourism, water supply etc. The continuous growth of population around coastal areas has increased the needs of fresh water and further, the need of a management planning for optimized use of water resources around an area. The mismanagement of these resources, combined to the accumulation of the population in the vicinity of coasts, has caused severe deterioration in such natural ecosystems with negative impacts to the surface water and the groundwater of coastal wetlands.

The sustainability of such sensitive hydrological ecosystems usually relies on groundwater, as the underlying aquifers operate as regulators for both quantity and quality of their waters. An adequate monitoring andmanagement scheme is essential to maintain the well-being of a groundwater system or even to consolidate a deteriorated one. Managed Aquifer Recharge (MAR) is a widely used solution for the treatment and the restoration of deteriorated aquifer systems. Water 
reuse and artificial recharge of groundwater is expected to increase as the population rises and the water demand increases, combined to the lack of availability of an adequate surface water storage [1]. Several MAR techniques have already been applied to different parts of the world [2-5], Europe [6], as well as to Mediterranean coastal hydro-systems with several casestudies such as in France [7] and Spain [8].

This article, analyses the experimental application of a MAR system in a semi-arid coastal wetland in Greece. The experiment includes a smart engineered MAR system that involves an optimized Pump \& Treat system integrated with an Aquifer Storage and Recovery (ASR) scheme in the pilot area. This scheme allows the abstraction of brackish groundwater from a deeper aquifer layer at a location close to the shoreline, direct treatment with Reverse Osmosis (RO) for desalination and finally the treated water recharge in a shallower layer.

\section{General Setting and Hydrogeological Conditions of the Study Area}

Marathon plain (approximately $40 \mathrm{~km}^{2}$ ) is located at the NE side of Attica in Greece, adjacent to the Mediterranean sea. The pilot area represents a typical Mediterranean semi-arid climate (Csa) with hot, dry summers and cool, wet winters according to Köppen's climate classification. The land uses of the area are domestic, touristic and mainly agricultural.

The geo-hydrological structure of the pilot area is formed between its natural boundaries which are the karstified marble units at the northern and western part of the plain, and the coastline at the southern part. At the eastern part, a swampy area forms a naturally occurring wetland that is hydraulically disconnected to the underlying alluvial layer (Figure 1). The aquifer system is mainly discharged into the Mediterranean Sea while the multiple drills and wells, pumping groundwater for agricultural purposes, are considered a significant loss of groundwater.

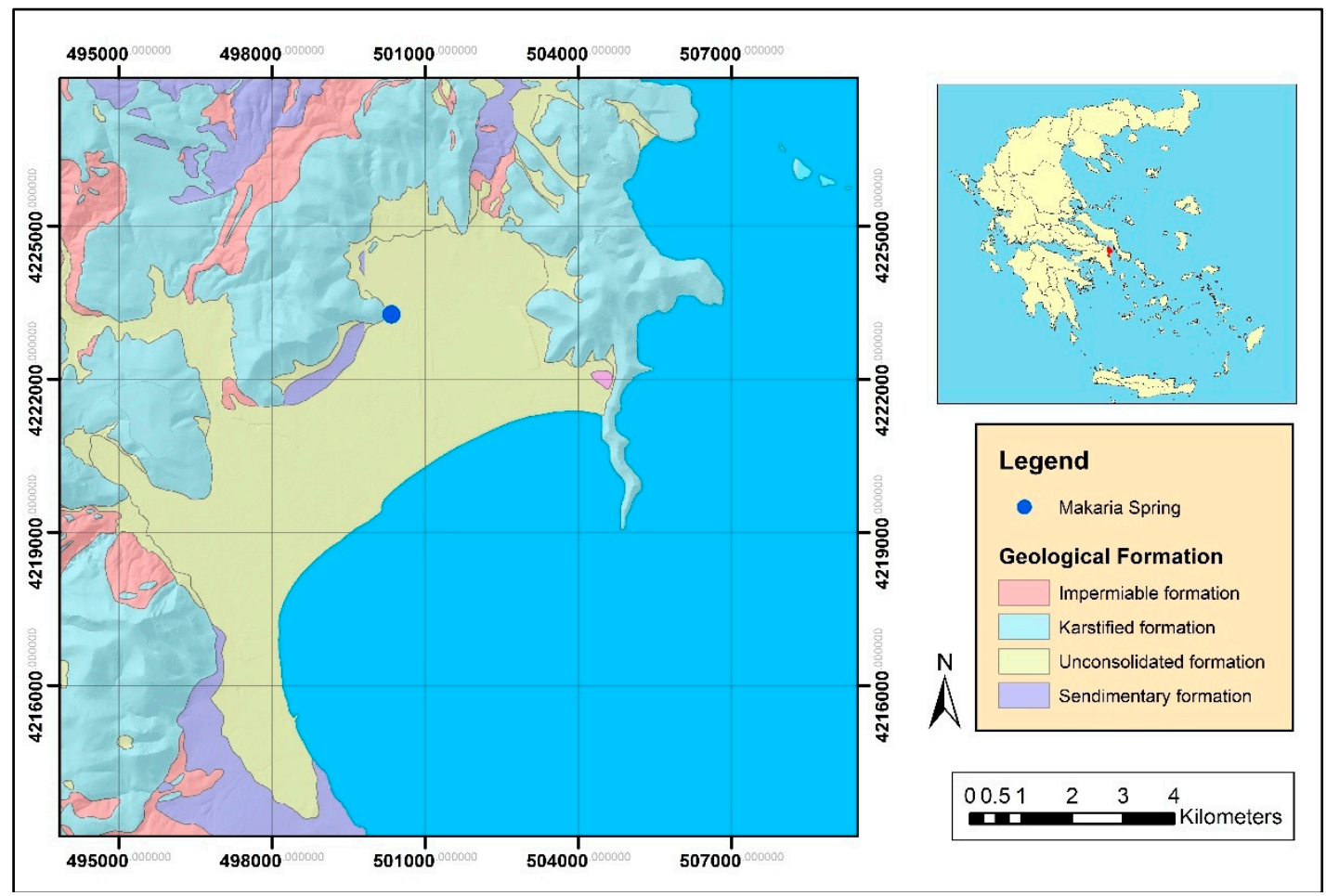

Figure 1. Hydrogeological system of Marathon.

The two major aquifer units of the area are the karstified marbles and the unconsolidated-alluvial formation. The two units are in hydraulic connection but their characteristics differ in terms of hydraulics, size and volume ofwater. The marble unit is divided in 5 different units, according to Melissaris and Stavropoulos [9] while their thickness exceeds $400 \mathrm{~m}$ and their hydraulic conductivity ranges between $10^{-5}$ and $10^{-4} \mathrm{~m} / \mathrm{s}$ [10]. The karstic aquifer discharges into the alluvial aquifer of Marathon plain and into the sea through diffuse flow and through 
multiple coastal and submarine springs. A major discharge point of the karstified marbles, is Makaria spring, at the NE part of the plain in "Marathon marbles" karstic unit. The mean discharge rate of Makaria spring has been estimated at $810 \mathrm{~m}^{3} / \mathrm{h} \mathrm{[11]} \mathrm{while} \mathrm{the} \mathrm{karstic} \mathrm{water} \mathrm{is} \mathrm{drained} \mathrm{to} \mathrm{a}$ wetland at the east side of the plain and to the sea. The unconsolidated aquifer is formed mainly in alluvial deposits and extends in Marathon plain. Itsthickness ranges between a few meters up to 80 $\mathrm{m}$ while it is a layer of lower permeability as the hydraulic conductivity varies from $10^{-6}$ to $10^{-5} \mathrm{~m} / \mathrm{s}$ [10]. The aquifer is recharged mainly through direct infiltration of precipitation, lateral inflows from the surrounding karstic aquifer, irrigation return inflows and through Makaria spring. The unconsolidated aquifer is composed of sediments with different grain size distribution (gravels, sands, clay, silty clay) and although it is considered to be a phreatic one, the occurrence of multiple clay lenses through the extend of the plain, forms a confined upper layer in different parts of the plain. This confined condition makes the monitoring and management of the granular unit difficult due to different hydrodynamic conditions in the study area.

Both karstic and unconsolidated aquifer layers suffer from seawater intrusion due to overpumping mainly for agricultural purposes through multiple wells and drills and due to the mismanagement of the two units [9]. The seawater encroachment is more pronounced in the surface layer (unconsolidated formation) as a result of the numerous boreholes that constructed throughout the years resulting from the easy and cheap accessibility to the unit.

The coastal hydro-system of Marathon includes a naturally occurring wetland that is part of the Schinias Marathon National Park and is located at the eastern part of the plain. According to the "Management Board of Schinias Marathon National Park", the wetland is of high importance for the ecosystem of the surrounding area as it is a natural habitat of reeds, trees, halophytic vegetation, wet meadows and of several species of migratory birds. The wetland is hydraulically connected to the sea and to the Olympic rowing center of Schinias, which is recharged by Makaria karstic spring through artificial channels. Every part of the hydro-system interacts with another. Nowadays, the wetland and the balance of the whole hydro-system of Marathon is endangered as it is already deteriorated due to mismanagement of water resources in the plain and the surrounding area. The problem has been widened mainly as a result of the overexploitation of the two aquifer layers of Marathon due to the extensive agricultural activities in the whole plain.

\section{Managed Aquifer Recharge and Freshwater Management through Subsurface Water Solutions (SWS)}

Coastal areas are densely populated areas considering that the half of the population around the world lives within $60 \mathrm{~km}$ of the shoreline [12]. Although these zones produce numerous socio-economic benefits, overpopulation often implies extensive needs of natural resources and fresh water. This leads to groundwater overexploitation, resulting in seawater encroachment in the mainland, upconing, seasonal water shortage, land subsistence or even disappearance of wetlands.

The need of groundwater protection in order to prevent further environmental implications has been pointed by the European Commission within the Water Framework Directive 2000/60/EC. In more detail, WFDpresents the need for the establishment of an action programme for integrated monitoring, management and protection of groundwater bodies, in terms of quality and quantity. As supplementary measures, Article 11(4) of WFD proposes the adaptation of an artificial recharge scheme for the remediation of aquifer layers.

The need for protection and reclamation of the groundwater systems has provoked the development of new MAR schemes and the evolution of the old ones. Subsurface Water Solutions (SWS) provide innovative and practical concepts, using cutting edge technologies in the idea of groundwater protection and advanced freshwater management in coastal areas. SWS offers coupled solutions for natural ecosystems with a technological approach in the view of artificial recharge in coastal zones, as many times, the already existing technologies can be inefficient in groundwater problems of coastal aquifers as a result of the existence of brackish and saltwater.SWS involve flexible installations (constructions) and equipment, easily adaptive to the field while they are built on novel designs that are controlled through ICT tools based on improved monitoring and 
modeling. These solutions have been tested in pilot scale [13] while they are applicable at a range of scales, from agricultural fields to small catchment area or even water well fields of cities.

There are three typical applications of SWS and there are presented in Figure 2:

Freshkeeper: the technique targets to protect abstraction wells against salinization, through a dual zone abstraction. The structure operates with multilevel wells in a way that freshwater is pumped from the shallow zone of the aquifer while brackish water is simultaneously pumped from the lower part of the aquifer, providing control over the freshwater-saltwater interface. The brackish pumped water will then be desalinated through smart, integrated systems such as Reverse Osmosis (RO) units and subsequently it can be used as an additional freshwater source.

ASR-coastal: Aquifer Storage and Recovery technologies are applied using a single vertical well for injection and recovery of groundwater. These schemes are successfully applied in freshwater aquifer but when it comes to saline reservoirs, ASR is not always suitable solution for a brackish groundwater environment due to losses caused by buoyancy effects (Zuurbier et al., 2015). ASR-coastal setup uses multiple wells penetrating in several aquifer depths in order to enable freshwater injection at the base of the aquifer and abstraction in shallow depths, near the top. Following this specific ASR pattern, the freshwater recovery in the brackish layer is more effective.

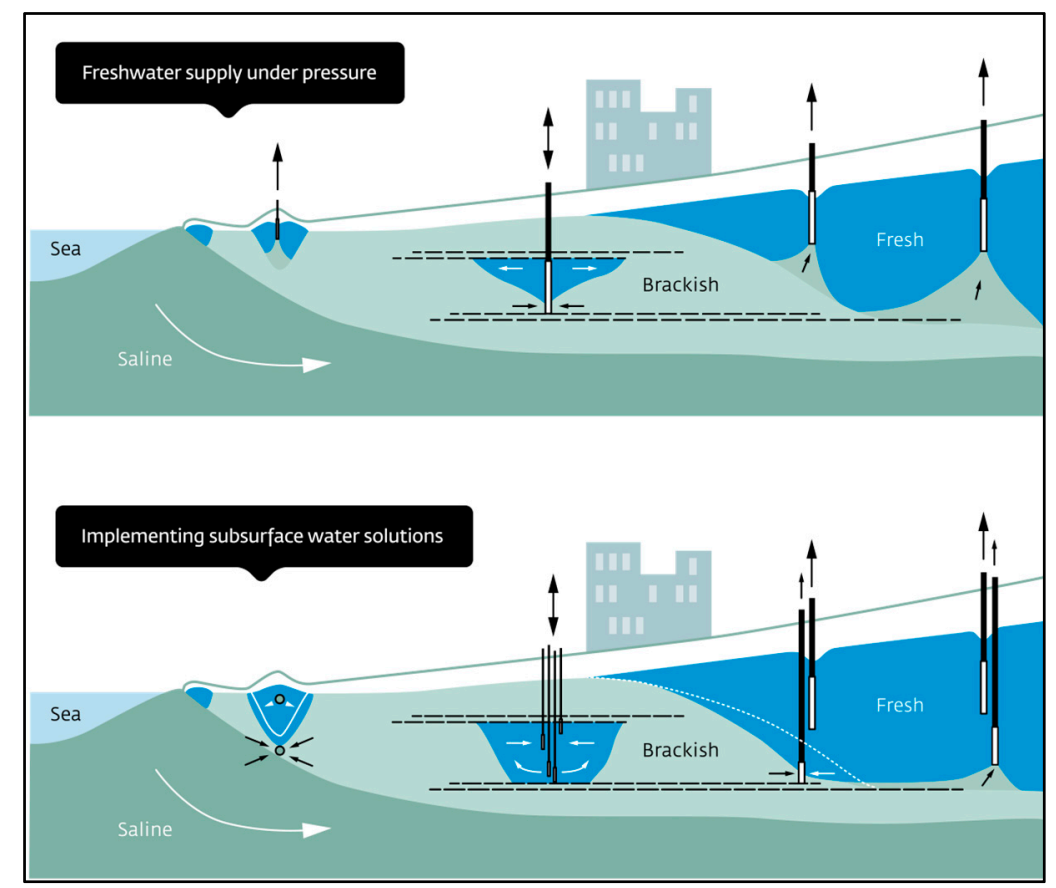

Figure 2. Advanced freshwater management in coastal zones through SWS: [14].

Freshmaker: The scope of the "Freshmaker" SWS, relies on freshwater lenses protection, maintenance and enlargement inside the groundwater mass of coastal aquifers. The solution combines the concept of "ASR" and "Freshkeeper" using instead of vertical, horizontal directional drilled wells (HDDW). The newly developed drilling technology (HDDW) allows the penetration in several depths along the length of the aquifer. The main setup consists of a deep HDDW, near the fresh-saltwater interface for brackish water abstraction and prevention of upconing and buoyancy effects, while the artificial recharge and recovery of freshwater occurs through a shollow HDDW. This scheme enables freshwater lenses enlargement and use of the surplus in periods of high demands.

\section{Application of SWS Concept at the Pilot Site of Marathon}

The coastal plain of Marathon forms an area with extensive agricultural land use, accommodating outdoor plant productions and greenhouses and a tourist resort that is overpopulated especially during summer period. Such activities in the area require high quality of 
water, while the main source of freshwater is the two aquifer layers of the plain. Mismanagement and irrational use of groundwater resources has led to seawater intrusion, seasonal imbalance between water supply and demand and shortage of available water so that the storage and supply cycle of the aquifers is fiercely affected. A MAR solution is vital for the restoration of the groundwater system, in terms of quality and quantity, as well as to restrain the effect of seawater intrusion in the aquifer.

In order to evaluate the applicability of the SWS in the more contaminated groundwater layer of Marathon (alluvial aquifer), a pilot setup was constructed at the eastern part of the plain, at Schinias area. Several technological advancements that were applied in the experimental sites of "Freshmaker", "ASR-coastal" and "Freshkeeper" solutions in the Netherlands [15] were adapted in the experimental site. The concept of Schinias pilot scheme is introduced in Figure 3.

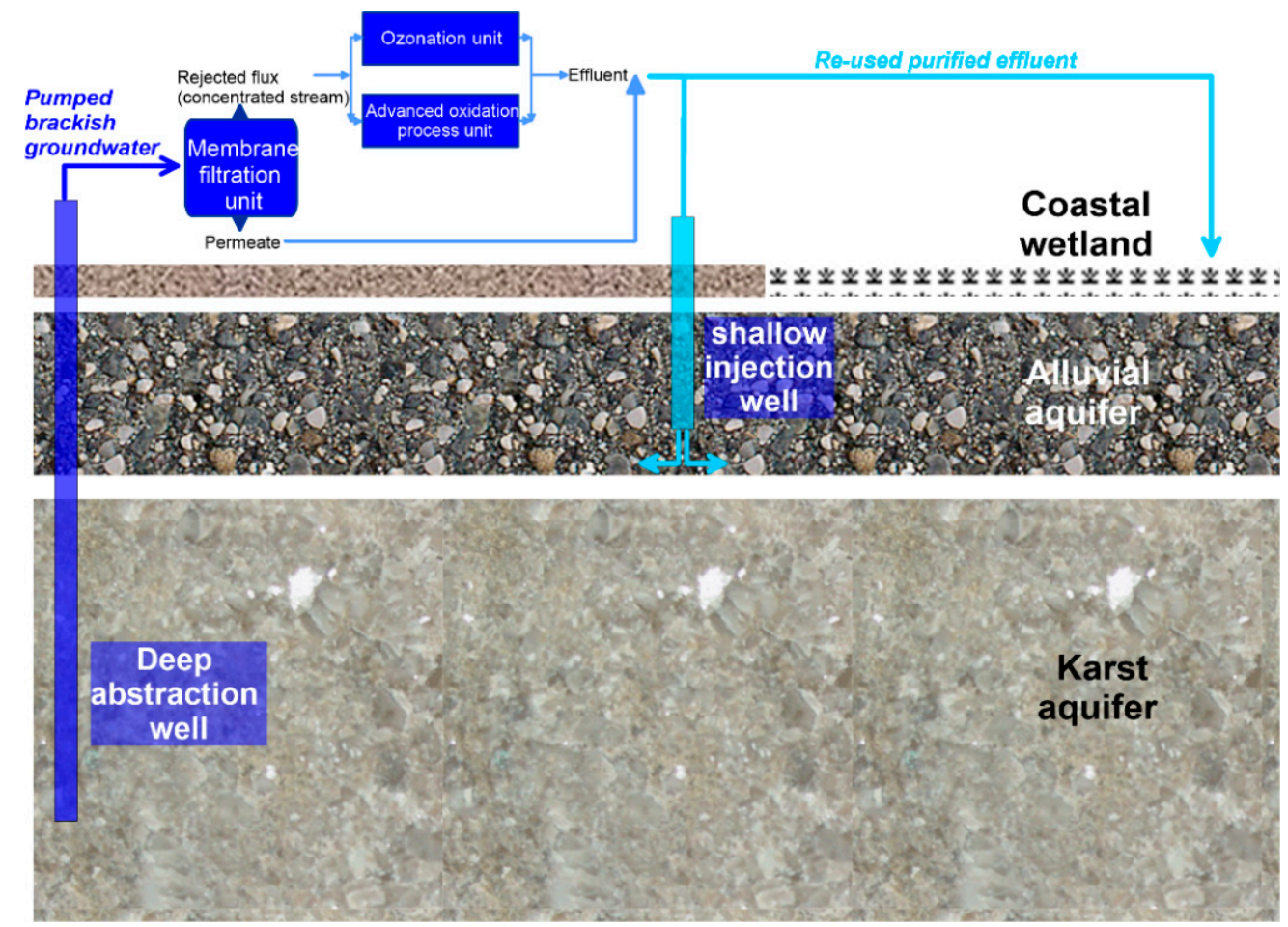

Figure 3. Schematic representation of experimental setup in Schinias pilot site.

The aim of the Schinias replication is the utilization of deep groundwater resources of better quality from the karstic aquifer, in order to recharge the upper saline unconsolidated formation. Before the injection, the karstic wateris adequately treated through novel pollution remediation techniques, in order to ensure the recharge of the upper aquifer with high quality water. The experiment targets to create a seawater intrusion barrier along the coast and to restore the -today degraded- wetland of Schinias.

The concept that presented in Figure 3, was adapted in Schinias field and designed taking into consideration the specific features of the hydrogeological system and the topography of the selected location as well as the available facilities in the area, in the idea of a cost-efficient planning and operation. The altered infrastructure of the pilot setup is shown in Figure 4.

The location used for the setup is the Olympic Rowing Center of Schinias due to the available facilities and the accessibility to the "Makaria" karstic spring channel that was used as a pumping point of karstic water. The quality of the injected groundwater, is safeguarded through an advanced water processing unit that was placed at the southern side of the Rowing Center and offers flexible treatment technologies for SWS schemes (Figure 5). The treatment techniques of the unit include an Advanced Oxidation Process (AOP) unit for the reduction/removal of organic pollutants and a Reverse Osmosis (RO) unit for the reduction of salinity (total dissolved solids) (Figure 5). Both AOP 
and $\mathrm{RO}$ units are controlled and monitored remotely, while the whole structure is flexible and mobile for future use in several pilot sites.

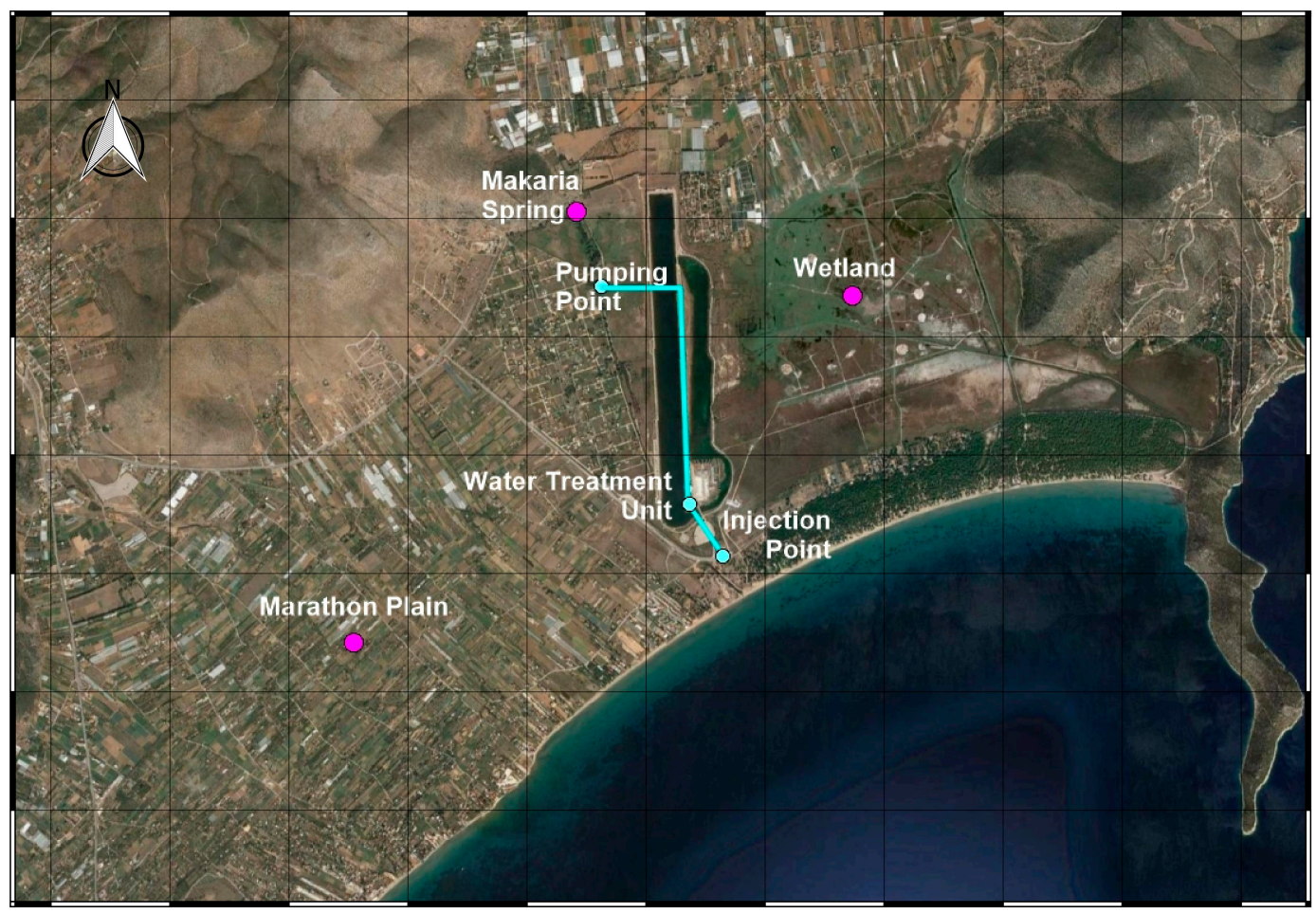

Figure 4. Experimental setup of a SWS in Schinias, Marathon plain.

After the treatment plant, the karstic water is sent through a pipe to the injection point that is located at the eastern part of the plain, at a distance of $300 \mathrm{~m}$ from the shoreline, where there is severe intrusion of seawater to the inland. The structure combines different "SWS" techniques as a vertical and an horizontal well (HDDW) have been drilled for the experimental scale aquifer desalination (Figure 5). Different scenarios will be followed during theexperiments by altering the abstraction and injection processes between the two wells.

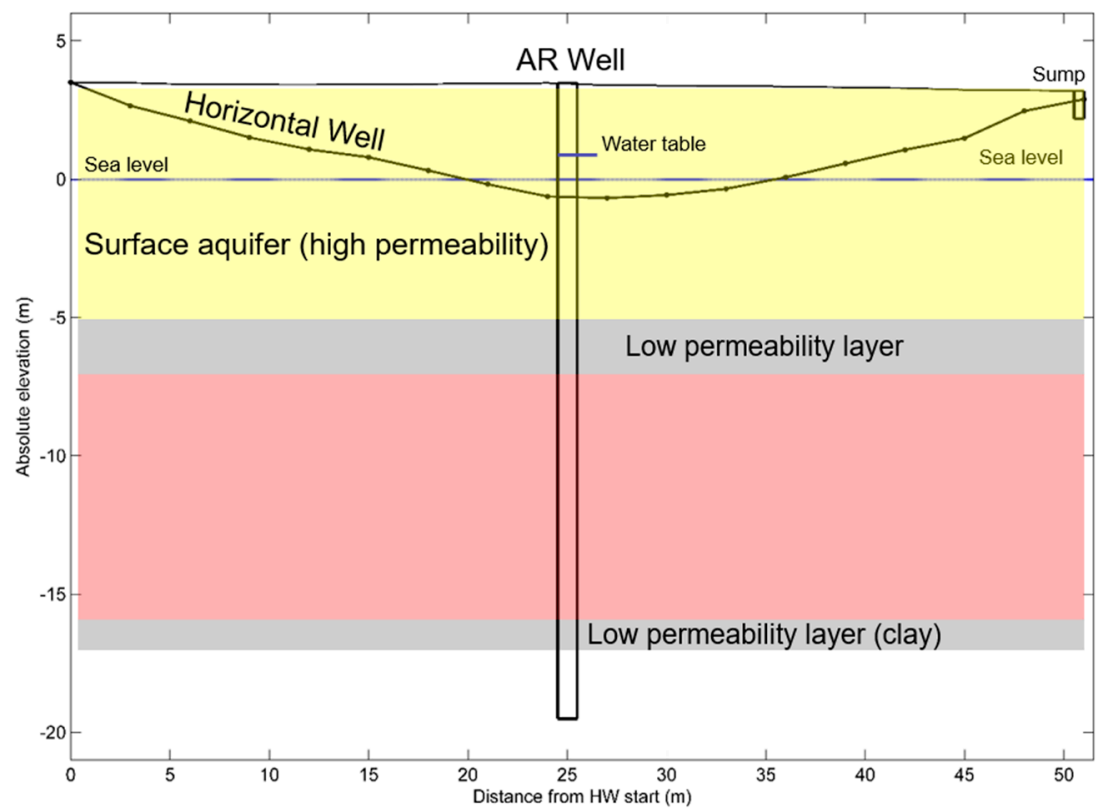

Figure 5. Managed aquifer recharge scheme of SWS. 


\section{Conclusions}

Schinias pilot site is an SWS experiment that focuses on the application of new MAR techniques in a semi-arid coastal aquifer. The expected results and the contribution of the specific project to the scientific and the local community are:

- Demonstration of how a currently unused water source (potentially polluted groundwater and surface water) can be turned into a source for protection, regeneration and financial sustainability for the area (and other similar ones throughout the Mediterranean).

- Development of flexible treatment technologies for SWS schemes, including Reverse Osmosis (RO) and Advanced Oxidation Methods. Merging new treatment technologies with SWS will broaden the range of source waters to be used in SWS applications.

- New ways to remotely control SWS systems, by developing ICT solutions based on wireless sensor networks that monitor water quality and water levels in the aquifers and the performance of treatment process.

- Potential large scale application of MAR at the plain of Marathon, targeting to the rehabilitation of the wetland and of the two aquifer layers, with main cause the sustainable use of groundwater in order to restrain the impact of seawater intrusion.

Author Contributions: M.P., A.K., K.M. and C.M. are responsible for the coordination of the pilot experiments, the involved field and modeling activities; D.I., C.C. and E.B. designed and constructed the R.O. \& A.O. unit; K.D. constructed the MAR infrastructure of the pilot site; A.Z. developed the database;K.R. and G.v.d.B. conceived the general concept of the SWS technologies.

Acknowledgments: This research is a part of SUBSOL-bringing coastal SUBsurface water SOLutions to the market Project. SUBSOL has received funding from the European Union's Horizon 2020 research and innovation programme under grant agreement No 642228

\section{References}

1. Bouwer, H. Artificial recharge of groundwater: hydrogeology and engineering. Hydrogeol. J. 2002, 10, 121-142, doi:10.1007/s10040-001-0182-4.

2. Xanke, J.; Goeppert, N.; Sawarieh, A.; Liesch, T.; Kinger, J.; Ali, W.; Hötzl, H.; Hadidi, K.; Goldscheider, N. Impact of managed aquifer recharge on the chemical and isotopic composition of a karst aquifer, Wala reservoir, Jordan. Hydrogeol. J.2015, 23, 1027-1040, do: 10.1007/s10040-015-1233-6.

3. Missimer, T; Drewes, J.; Amy, G.; Maliva, R; Keller, S. Restoration of Wadi Aquifers by Artificial Recharge with Treated Waste Water. Ground Water2012, 50, 514-527.

4. Sasidharan, S.; Bradford, S.A.; Šimunek, J.; Torkzaban, S.; Vanderzalm, J. Transport and fate of viruses in sediment and stormwater from a Managed Aquifer Recharge site. J. Hydrol. 2017, 555, 724-735.

5. Urióstegui, S.H.; Bibby, R.K.; Esser, B.K.; Clark, J.F. Quantifying groundwater travel time near managed recharge operation using $35 S$ as an intrinsic tracer. J. Hydrol. 2016, 543, 145-154.

6. Sprenger, C; Hartog, N.; Hernández, M.; Vilanova, E.; Grützmacher, G.; Scheibler, F.; Hannappe, S. Inventory of managed aquifer recharge sites in Europe: historical development, current situation and perspectives. Hydrogeol. J. 2017, 25, 1909-1922.

7. Casanova, J.; Devau, N.; Pettenati, M. Managed Aquifer Recharge: An Overview of Issues and Options. Integr. Groundw. Manag. 2016, doi:10.1007/978-3-319-23576-9_16.

8. García-Menéndez, O.; Ballesteros, B.; Renau-Pruñonosa, A.; Morell, I.; Mochales, T.; Ibarra, P.; Rubio, F. Using electrical resistivity tomography to assess the effectiveness of managed aquifer recharge in a salinized coastal aquifer. Environ. Monit. Assess. 2018, 192, 100.

9. Melissaris, P.; Stavropoulos, X. Hydrogeological Assessment of the Coastal Plain of Marathon, Attica 1999; Report submitted to the Ministry of Agriculture; Department of Land Reclamation: Athens, Greece, 1999.

10. Siemos, N. Evaluation of Water Resources in Attica \& Islands of Argosaronic Gulf 2010; Institute of Geological and Mineral Exploration: Athens, Greece, 2010; p. 148.

11. Perleros, V. Geological-Hydrogeological Assessment. In Technical Report on Integrated Assessment for Planning and Development Including Supporting Research Activities for the Construction ofSchinias Olympic Rowing and Canoeing Centre 2001; General Secretariat for Public Works: Athens, Greece, 2001. 
12. Essing, G. Improving fresh groundwater supply-problems and solutions. Ocean Coast. Manag.2001, 44, 429-449.

13. Zuurbier, K.; Raat, K.J.; Paalman, M.; Oosterhof, A.T.; Stuyfzand, P.J. How Subsurface Water Technologies (SWT) can Provide Robust, Effective, and Cost-Efficient Solutions for Freshwater Management in Coastal Zones. Water Resour. Manag. 2017, 31, 671-687.

14. SUBSOL Subsurface Water Solutions. Available online: http://www.subsol.org/ (accessed on 10 February 2018).

15. Zuurbier, K.; Kooiman, J.; Groen, M.; Maas, B.; Stuyfzand, P. Enabling Successful Aquifer Storage and Recovery of Freshwater Using Horizontal Directional Drilled Wells in Coastal Aquifers. J. Hydrol. Eng. 2015, 20, B4014003.

(C) 2018 by the authors. Licensee MDPI, Basel, Switzerland. This article is an open access article distributed under the terms and conditions of the Creative Commons Attribution (CC BY) license (http://creativecommons.org/licenses/by/4.0/). 